\title{
JAPÓN URBANO \\ REVALORACIONES Y COMPRENSIÓN \\ DE LA CIUDAD NIPONA
}

TYANA SANTINI 


\section{TYANA SANTINI}

PhD y maestría, Universidad de Kioto, Japón. Arquitecta, Universidad ORT Uruguay. Profesora asistente de la Cátedra de Historia y Teoría, Universidad ORT Uruguay. 


\section{RESUMEN \\ ABSTRACT}

En las últimas décadas en el ambiente académico internacional han aparecido numerosos estudios sobre las ciudades de Japón, basados en la premisa de que las expresiones materiales de una cultura reflejan su historia, sus valores y su organización social. Luego de una revisión, presentada a modo de introducción, de los cambios de actitud occidental hacia la ciudad japonesa, este trabajo examina las características que hacen de los centros urbanos de Japón un tema de interés para otras culturas. La discusión se organiza bajo tres categorías: 1) «Estructuradores desarticulados», que analiza la naturaleza de los estructuradores legales y materiales que dan forma a la ciudad; 2) «Materialidad y memoria», donde se examina la relación del pueblo japonés con la materialidad de sus ciudades, para comprender los intensos procesos de renovación urbana; y 3) «Vitalidad», que considera las causas y características de la activa vida urbana japonesa, tema repetidamente destacado en los trabajos occidentales.

Sin intención de obtener enseñanzas aplicables a otros contextos culturales, este estudio se propone examinar las distintas lógicas de las ciudades de Japón con el fin de enriquecer nuestra comprensión de los factores que afectan el espacio urbano.

Palabras clave: Japón, paisaje urbano, estructuradores, preservación patrimonial, vitalidad.

In the past decades, numerous studies on the cities of Japan have been published in the international academic environment based on the premise that the material expressions of a culture reflect its history, values, and social organization. After a review of the changes in Western attitudes towards the Japanese city, this paper examines the characteristics that make the urban centers of Japan a topic of interest for other cultures. The discussion is organized under three categories: 1) Ambiguous structures, where the nature of the normative framework and layout that shape the city are analyzed; 2) Materiality and memory, where the relation of the Japanese people with the materiality of their cities is examined in order to understand the intense processes of urban renewal; 3) Vitality, where the causes and characteristics of the active Japanese urban life, a subject repeatedly emphasized in Western works, are considered.

Without intending to draw lessons applicable to other cultural contexts, this study will examine the different logics Japanese cities in order to enrich our understanding of the factors affecting urban space.

Key Words: Japan, cityscape, urban structures, heritage preservation, vitality. 


\section{INTRODUCCIÓN. APRECIACIÓN Y ESTUDIO DE LA CIUDAD JAPONESA ${ }^{1}$}

A mediados del siglo XIX Japón comenzó un proceso de reapertura al mundo, que terminaba con el prolongado período de reclusión -Sakoku (1639-1854)-. Viajeros occidentales comenzaron a visitar el país, muchos de ellos motivados por la admiración que despertaban sus artes. Los grabados ukyo-e sirvieron de inspiración al movimiento llamado «japonismo», mientras que las artes decorativas y la arquitectura tradicional fueron abundantemente elogiadas. Sin embargo, las ciudades de Japón no recibieron el mismo interés que las demás expresiones materiales de su cultura.

Los viajeros occidentales manifestaban asombro frente a la aparente falta de cuidado estético de las ciudades, que contrastaba con la sofisticación de sus artes. Si bien los interiores de las viviendas eran apreciados, su aspecto exterior era repetidamente criticado. Algunas características, como la limpieza y la vitalidad de las ciudades, eran muy valoradas, pero el regular paisaje urbano era calificado invariablemente como monótono y sombrío. La mayoría de los observadores occidentales no vio más allá de los referentes urbanos occidentales faltantes, como las plazas, iglesias o pavimentos, por lo que las ciudades japonesas eran vistas como primitivas. Frank Lloyd Wright, por ejemplo, quien apreció el carácter pintoresco de las ciudades

1. Esta sección está basada en la investigación parcialmente publicada en: Santini, T. y Taji, T.: Appreciation of Japanese cityscape in Western Publications from Meiji Restoration until WW2, Proceedings of the International Symposium on Architectural Interchanges in Asia, Corea, 2012 de Japón, se refiere a Tokio como una «aldea gigante» (Wright, 1967 [1912], p. 94).

Las críticas occidentales hacia el entorno urbano japonés se agudizaron una vez comenzado el proceso de «modernización». Para evitar la suerte de otros países asiáticos que se encontraban bajo el dominio europeo, Japón emprendió una formidable reestructuración conocida como «Restauración Meiji» (1868). Rápidamente el país incorporó tecnologías y estructuras de organización occidentales (figura 1). Desde el punto de vista urbano, la implementación de conceptos de planeamiento europeos y mejoras en infraestructura eran elogiadas, mientras que las críticas estaban dirigidas hacia la adopción de estilos constructivos europeos. El paisaje urbano que había sido considerado «monótono» comenzó a ser percibido como «armonioso» cuando la mezcla de estilos y técnicas constructivas tomó dominio de la ciudad. Bruno Taut, quien pasó largos años en ese país estudiando su arquitectura, arte y cultura, descartó por entero el análisis de sus ciudades por considerar que de urbanismo, como ciencia o arte, ningún estudio podría hacerse en Japón (Taut, 1937). ${ }^{2}$

El interés de arquitectos y urbanistas occidentales por las ciudades japonesas no comenzó hasta la segunda mitad del siglo $X X$, primero indirectamente a través de las obras del movimiento metabolista, y luego mediante publicaciones y traducciones de estudios he-

2. Los únicos profesionales occidentales interesados en la ciudad japonesa fueron geógrafos como Robert B. Hall, Glenn T. Trewartha, y Ludwig Mecking, entre otros. 
chos por arquitectos y otros autores japoneses, como el historiador Teiji Itō (1922-2010).

Durante la década del 50 había comenzado en Japón la búsqueda de una nueva comprensión de la ciudad liderada por el Grupo de Investigación de Diseño Urbano, formado 1956, entre cuyos integrantes estaban el arquitecto Arata Isozaki (1931-) y Teiji Itō. Para ese entonces las limitaciones del planeamiento funcionalista occidental se habían hecho evidentes y los arquitectos japoneses comenzaron a mirar a su ciudad en busca de soluciones (Oshima, 2016). Muchos de ellos estuvieron inspirados en el trabajo de Wajiro Kon (1888-1973) y su obra de los años veinte Modernología, donde sostenía que el planeamiento urbano debía basarse en el comportamiento de la población (Kuroishi, 2016). Esta postura se alineaba con la tendencia internacional de estudios urbanos basados en el análisis de la espacialidad, percepción de autores como Kevin Lynch (19181984), Gordon Cullen (1914-1994), Edward T. Hall (19142009), y Christopher Alexander (1936-). A diferencia de las tendencias anteriores del urbanismo occidental, este enfoque resultaba apropiado para el estudio de las irregulares ciudades japonesas. La valoración de la realidad del paisaje urbano japonés ganó aceptación rápidamente, y el contraste entre lo tradicional y lo contemporáneo se volvió la imagen más representativa de la ciudad japonesa.

Esta revaloración, sumada al aumento del intercambio profesional y académico, estimuló la publicación de estudios sobre Japón orientados al público extranjero. En este tipo de trabajos se reflexiona acerca de la relación entre la cultura japonesa y la producción del espacio, lo que lleva a la creación de varios nuevos conceptos. En 1978 Fumihiko Maki (1928-) introduce el concepto de oku -literalmente: espacio interior- aplicado a la ciudad. Maki advierte que si bien este concepto está relacionado con el espacio medular, no debe confundirse con un centro urbano en el sentido europeo, más visible y ocupado por construcciones representativas, como la iglesia. En Japón el oku está oculto tras capas envolventes de espacios, y está generalmente exento de toda presencia física, como los intrincados caminos de los santuarios sintoístas que conducen a un remate vacío. ${ }^{3}$ Según Maki, la espacialidad oku es producto de una cultura que niega los objetos o símbolos absolutos, como la noción de centro (Maki, 1978). Otra noción importante de la espacialidad japonesa que fue reinterpretada en esa época es el concepto de ma -literalmente: intervalo o pausa-. ${ }^{4}$ Tradicionalmente, en la arquitectura japonesa, ma refiere al espacio lineal estandarizado entre dos columnas, utilizado como unidad de medida. En la nueva interpretación, ma refiere a que el énfasis de la percepción del espacio no está en los objetos sino en el espacio intermedio. En el entorno urbano, este tipo de percepción permite una lectura del espacio diferente a la de las lógicas occidentales, enfocadas en lo físico (Neiva y Righi, 2008). A estos traba-

3. Maki hace alusión al trabajo del filósofo francés Roland Barthes (1915-1980), quien al analizar la ciudad de Tokio encuentra que a pesar de tener un centro, el palacio imperial, este se encuentra vacío de significado.

4. Este concepto fue reexaminado en un principio por el historiador Teiji Itō y Arata Isozaki a principios de la década del 6o, y el análisis que el arquitecto alemán Günter Nitschke hizo en la publicación titulada Ma-The Japanese Sense of Place popularizó ese concepto en Occidente. 


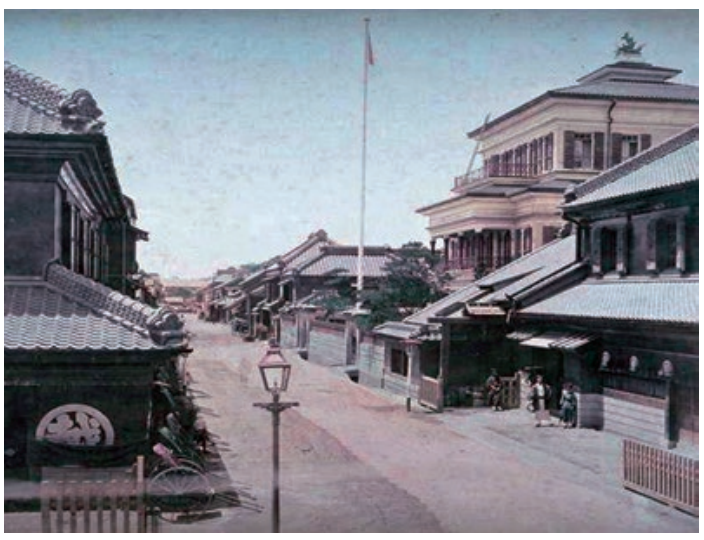

01.

jos clave en la definición de un nuevo vocabulario para la espacialidad japonesa se les suman estudios como El orden escondido (1989), de Yoshinobu Ashihara (1918-2003), y reflexiones de reconocidos arquitectos, como Kisho Kurokawa (1934-2007) en Redescubriendo el espacio japonés (1988).

Actualmente, la búsqueda de lo auténticamente japonés de la segunda mitad del siglo XX no es bien recibida, por verse como una continuación del mito del carácter único de la cultura japonesa (Loeffler, 2013). De todas formas, las experiencias de esta época dieron origen a la comprensión de la ciudad japonesa en sus propios términos y abrieron un campo de investigación sumamente fértil. Hoy, junto a los japoneses dedicados al estudio de sus ciudades se encuentra un gran número de académicos occidentales que analizan el tema desde varias perspectivas. Entre los autores más importantes están Botond Bognar y Barrie Shelton, quienes analizan mayormente la ciudad contemporánea; Carola Hein y André Sorensen, que se centran en el estudio detallado del planeamiento y desarrollo histórico urbano; Paul Waley y Nicolas Fiévé quienes analizan la ciudad desde la perspectiva histórica, y el geógrafo y filósofo francés Augustin Berque, que aporta un enfoque más teórico.
01.

Tokio, finales del siglo xix.

Mezcla de estilos arquitectónicos japoneses y occidentales.
En las siguientes secciones de este trabajo se analizan las características de las ciudades de Japón que han estimulado el interés internacional. Luego de una revisión de los temas tratados más recurrentemente en textos sobre las ciudades japonesas de autores occidentales, 5 se realizó una reclasificación de estos bajo tres categorías: 1) «estructuradores desarticulados», referente a la naturaleza de estructuradores legales y materiales que influyen en la formalidad de la ciudad; 2 ) la relación entre «materialidad y la memoria del pueblo japonés», que ayuda a comprender los intensos procesos de renovación de la ciudad; y 3) la «vitalidad» de las ciudades, que aborda el tema del estilo de vida urbano.

La discusión de cada una de estas categorías integra las visiones de autores japoneses y occidentales, sumadas a observaciones nacidas de la investigación de archivo y campo propias. El propósito de esta discusión es examinar las distintas lógicas del espacio urbano japonés con el fin de enriquecer la comprensión de los factores que influyen en la formación de las ciudades.

Si bien la importancia de las ciudades de Tokio y Kioto las convierte en las más mencionadas, las categorías

5. Los textos revisados incluyen títulos de autores sudamericanos. Ver bibliografía. 
02

Matsue. Estudio de generación de calles y callejones no planificados en una gran manzana.

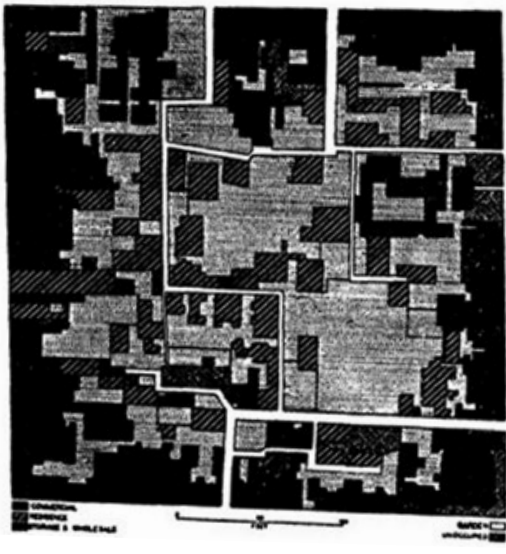

02 aquí tratadas refieren a características que son comunes a la mayoría de las ciudades del país, a pesar de tener trazados, orígenes y desarrollos muy disímiles.

\section{ESTRUCTURADORES DESARTICULADOS}

La aplicación de planes urbanos y otros estructuradores legales que dan forma a la ciudad tienen en el Japón contemporáneo un carácter mucho más flexible que en la tradición urbana occidental. Las ciudades japonesas tuvieron cuatro etapas de crecimiento vertiginoso: luego de la Restauración Meiji; luego del crecimiento económico de la primera posguerra; tras la reconstrucción seguida a la Segunda Guerra Mundial; y finalmente tras el gran boom económico de los años ochenta. A partir de la Restauración Meiji se instituyó una serie de planificaciones para la renovación de los centros urbanos basadas en modelos occidentales, europeos para desarrollos locales y estadounidenses para el uso del suelo y la zonificación (Masser, Shapira y Edgington, 1994). Una característica notada por Ashihara (1992) es que en Japón los planes urbanos se llevaron a cabo de forma parcial y con interminables modificaciones, admitiendo además muchísimas excepciones a las regulaciones (Ashihara, 1992).
Las inversiones del Estado fueron dedicadas principalmente a realizar grandes intervenciones de obra pública e infraestructura, priorizando el crecimiento económico frente a la creación de espacios públicos, y dejando el desarrollo de las áreas residenciales en manos del sector privado, tendiente a la especulación (Sorensen, 2004). Este escenario dificultó la mejora de las condiciones de áreas residenciales, que proporcionalmente representan el mayor espacio de la ciudad. Las normativas municipales referentes a zonas residenciales son estrictas respecto de las prevenciones antisísmicas y antiincendios, pero no proveen lineamientos precisos en cuanto al diseño urbano. Por otra parte, la tradición de autogobierno y fuerte independencia de los barrios heredadas de períodos anteriores a la restauración (Sorensen, 2004) continúan siendo un límite para la potestad de las autoridades municipales a la hora de tomar decisiones sobre áreas residenciales. ${ }^{6}$

Esta forma de encarar el planeamiento urbano se hace visible en el trazado de la ciudad contemporá-

6. Existen interpretaciones encontradas sobre este tema. Mientras que Sorensen $(2001,2004)$ entiende la laxa regulación como un desinterés del gobierno en invertir en el bienestar de la población, Ashihara (1992) explica que esta tendencia se mantiene debido a la resistencia de los japoneses a renunciar a la libertad en aras de la regularidad de formas. 


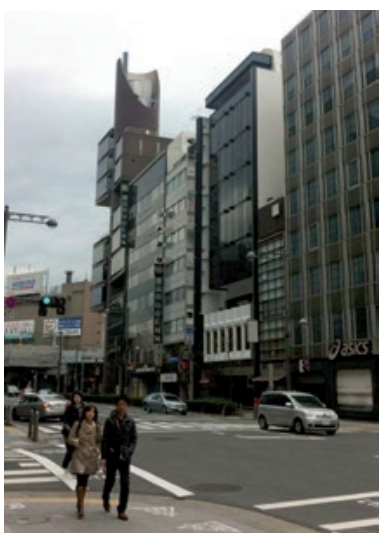

03.

nea, formada por pequeñas islas de desarrollo planeado sobre un fondo de crecimiento desordenado donde los trazados originales son relativamente mantenidos (Sorensen, 2004). En ciudades de origen militar, como Tokio, donde las calles se generaron de manera informal siguiendo las lógicas del relieve natural (Maki, 1978), la adaptación del trazado a modelos de desarrollo occidentales fue particularmente difícil. Kioto, por otro lado, una de las pocas ciudades diseñada originalmente siguiendo el modelo de trazado ortogonal de las capitales chinas, tenía una base que resultó más apta para la adaptación a modelos urbanos occidentales. De todas formas, incluso en Kioto la estructura interna de las grandes manzanas y gran parte de su crecimiento responden a esquemas que siguen un patrón sin consistencia geométrica (figura 2), responsable en gran parte de la espacialidad oku explicada por Maki. Las intervenciones por parte de los gobiernos municipales suceden mayormente en las avenidas y calles principales (figura 3), mientras que las calles secundarias (figura 4), sin aceras ni retiros, y los incontables callejones (figura 5) -roji- mantienen el carácter de la ciudad preindustrial. Actualmente la tendencia no se inclina a la renovación de la ciudad para adaptarla a los estándares occidentales, sino que se adapta la tecnología para
03

\author{
Tokio, 2014. Ejemplo de calle \\ principal. Distrito Ginza. \\ Edificio Shizuoka Broadcasting \\ de Kenzo Tange al fondo.
}

servir a la ciudad. En otras palabras, ahora no se amplían las calles sino que se achican los autos.

El intrincado trazado original de las ciudades japonesas se debe en parte al fraccionamiento irregular de las áreas rurales que pasaron a formar parte del territorio urbano (Neiva y Righi, 2008). Este fraccionamiento irregular, con origen en sistemas de propiedad anteriores a la restauración, se hizo aun más complejo después de la reforma agraria de la ocupación estadounidense, que fomentó la subdivisión de los terrenos en pequeñas parcelas (Sorensen, 2001). A consecuencia de estas prácticas, las formas y tamaños de gran parte de los lotes urbanos son sumamente variados. Al mismo tiempo, siguiendo con arraigadas tradiciones del régimen de propiedad rural, los dueños de lotes urbanos están autorizados a subdividirlos con considerable libertad, lo que aumenta la complejidad formal de los padrones. El alto impuesto nacional a la herencia es una de las principales causas de subdivisión (Bognar, 1997). Para poder afrontar el pago del impuesto, una respuesta común es vender una sección del terreno, lo que resulta en un gran número de lotes en forma de bandera (Osaragi, 2014) (figura 6). La situación legal del sistema catastral es tan compleja que la estandarización de lotes por parte de las autoridades se vuelve prácticamente imposible (Aveline-Dubach, 2014). A 
04.

Osaka, 2015. Ejemplo de calle

secundaria en zona comercial.

El tránsito vehicular y el peatonal comparten la calle.

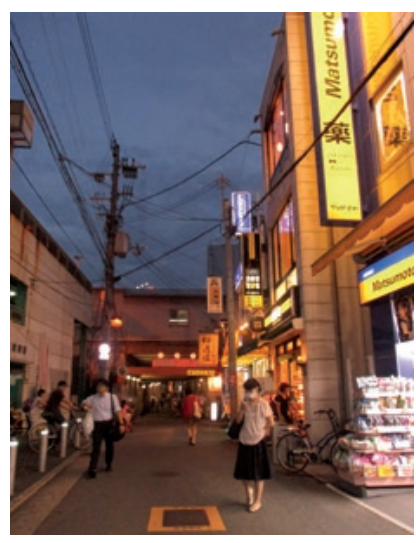

02.

consecuencia de la irregularidad de los terrenos, junto a la alta proporción de área construible, las estructuras que ocupan estos lotes también tienen formas y proporciones irregulares (Ashihara, 1992) que le dan a la ciudad japonesa su característico paisaje urbano sumamente variado.

Otra razón que contribuye a la diversidad del perfil urbano es la relativa libertad que admiten las regulaciones con respecto a la formalidad y terminaciones de las construcciones (figuras 7 y 8 ). Por otra parte, el desarrollo en altura ocurre en los frentes de las calles principales, mientras que sobre las calles y callejones secundarios se mantienen las viviendas unifamiliares y edificios de baja altura, lo cual resulta en un perfil que contrasta con el de la mayoría de las ciudades occidentales (Shelton, 1999) (figura 9). Los centros de las ciudades japonesas están formados en su mayoría por edificios de media altura, ${ }^{7}$ mientras que el paisaje suburbano sigue dominado por viviendas unifamiliares a pesar de la escasez de tierra donde construir. Contrariamente a lo que ocurre en áreas urbanas centrales, la homogeneidad de la ciudad tradicional japo-

7. En Tokio el 70 por ciento de las viviendas son apartamentos, de los cuales aproximadamente la mitad son de cinco pisos o menos, mientras que en Kioto el total de viviendas en apartamento es del 40 por ciento de los que un 64 por ciento son de cinco pisos o menos. nesa está siendo en parte recuperada en los suburbios debido a la proliferación de viviendas prefabricadas de grandes corporaciones, como Daiwa, Panahomes, y las crecientes Toyota Housing Corporation y Muji Homes (figura 10). De todas formas, a ambos tipos de paisaje se añade un número importante de complementos, como carteles, infraestructura eléctrica, portones, y otros varios aditamentos.

Entre toda esta densa composición urbana se encuentran las escasas áreas públicas. Al igual que en la mayoría de las ciudades asiáticas, en Japón no existen las plazas en el sentido occidental de centro de actividad en torno al cual se ubican edificios representativos del poder, como la iglesia. En Japón los espacios públicos por excelencia han sido tradicionalmente las calles. Según Kurokawa (1991), las calles de Japón no sólo cumplen el rol de las plazas occidentales uniendo a los ciudadanos con la vida pública, sino que tienen además la doble naturaleza de espacio urbano y residencial, posiblemente en alusión al límite ambiguo existente entre el espacio privado y el público en las calles secundarias y callejones. Por otro lado, los jardines y explanadas en torno a los templos budistas y santuarios sintoístas hacen también las veces de plazas, alojando mercados y festividades. El concepto de parque como área independiente de los edificios religiosos no apareció en Japón hasta 
05.

PÁGINA OPUESTA

\section{Kioto, 2015. Ejemplo de callejón o roji en zona residencial. En estos callejones el límite entre lo público y lo privado es ambiguo.}

después de la Restauración Meiji (Sorensen, 2004). Por esa razón, muchos de los parques urbanos presentes en las ciudades actuales fueron hechos en las pocas áreas libres existentes de los jardines de villas propiedad de las clases nobles de la época anterior a la Restauración, como el parque Ueno. Hay también una variedad de espacios públicos de pequeña superficie que surgieron de áreas residuales no planeadas (Inui y Nishida, 2012) (figura 11), que complementan las escasas áreas públicas de las ciudades japonesas.

Todas las características discutidas anteriormente están condicionadas por los estructuradores legales y físicos que, con ciertas variaciones, son comunes a todas las ciudades japonesas y son los responsables de darles un carácter formal distintivo.

\section{MATERIALIDAD Y MEMORIA}

En el proyecto presentado por Japón para la Bienal de Venecia de 2010 llamado Tokyo Metabolizing se mostró un video con una vista aérea de una sección de Tokio donde se veían los cambios acelerados en las construcciones (Inui \& Nishida, 2012).8 Esta realidad de constante cambio de las ciudades de Japón que comenzó a partir de la Restauración llevó a los arquitectos de este país a entender el entorno urbano en términos particulares. Para Isozaki (1993 [1966]), la ciudad se encuentra en estado líquido de reproducción y división orgánica, mientras que para Maki la ciudad favorece las fluctuaciones y la fluidez (Bognar, 1997).

8. El proyecto de la Bienal de 2010 fue presentado por Ryue Nishizawa Koh Kitayama y Yoshiharu Tsukamoto.
La lista de razones económico-legales que explican este dinamismo es extensa. La tierra es cara y escasa, la industria de bienes raíces es especulativa, y la enorme competencia en la industria comercial obliga a la constante renovación que la afluencia económica permite. Los altos impuestos a la herencia y bienes promueven a su vez el continuo reajuste y cambio de manos de propiedades en áreas residenciales. Al mismo tiempo, durante la burbuja inmobiliaria de los años ochenta un gran número de construcciones fueron adquiridas en terrenos bajo el régimen de alquiler Ilamado shakuchiken (Aveline-Dubach, 2014; Brasor y Tsubuku, 2011). Ser propietario de una casa en un terreno alquilado, generalmente por veinte o cincuenta años, implica que una vez terminado el plazo el dueño de la construcción deba removerla del terreno, a su costo. Este complejo contexto promueve la demolición. Generalmente en Japón no se tiene demasiado reparo en reemplazar edificios, independientemente de los materiales de la construcción. Edificios de hormigón y mampostería son tan fácilmente reemplazados como los de madera (Bognar, 1997; Ashihara, 1992). Construcciones de importante valor arquitectónico son igualmente demolidas sin que haya resistencia de los profesionales o los ciudadanos, como el City Hall, de Kenzo Tange, que fue descartado, demolido y reemplazado por otro también construido por Tange en otra área de la ciudad.

Si bien las explicaciones económicas presentadas anteriormente aclaran parcialmente el alto grado de reemplazo edilicio, el desapego por lo material debe ser también entendido con base en términos culturales, 


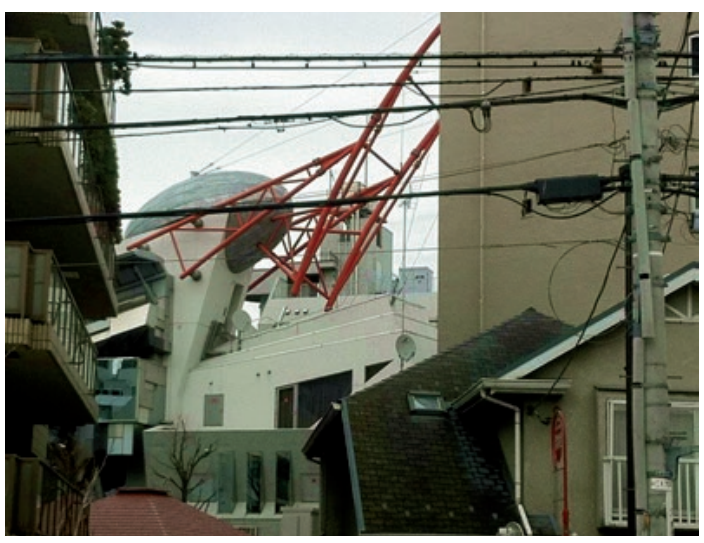

06.

particularmente con el concepto budista de transitoriedad (mujō). A pesar de que la tradición budista es compartida por varios países asiáticos, se entiende que en Japón la incorporación de este concepto a la cultura es más intensa por los constantes desastres naturales (Berque, 1991; Shelton, 1999; Bognar, 1997). El historiador Daniel J. Boorstin reconoce actitudes diferentes hacia el tiempo por parte las culturas occidental y japonesa, y ellas se ven reflejadas en sus construcciones. En Occidente, donde la naturaleza es percibida como hostil, las pesadas construcciones aspiran a la eternidad en un intento de negar la mortalidad. En Japón, sin embargo, el tiempo no es algo que haya que vencer sino que se vive aceptando sus leyes (Boorstin, 1986; Ashihara, 1992). De hecho, el carácter transitorio y efímero de la vivienda es enaltecido en uno de los textos más importantes de la literatura medieval japonesa, Hōjōki, de 1212, referencia obligada en los estudios de arquitectura de Japón.

La aceptación de la transitoriedad lleva al pueblo japonés a asignarle a lo material un valor distinto al que tiene en la tradición occidental. Una característica de la ciudad tradicional que sorprendía a los visitantes extranjeros era la ausencia de monumentos. De la misma forma, asombraba que los nombres de las calles no estuvieran dedicados a héroes nacionales ni a personajes

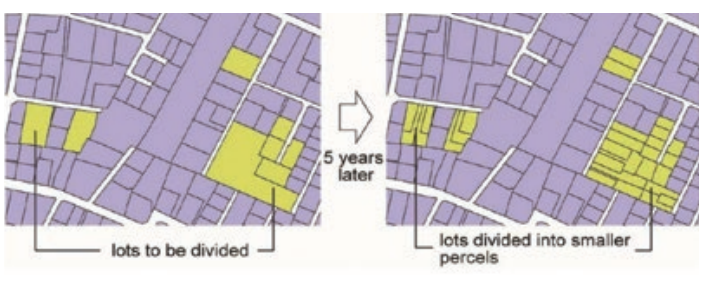

07.

06.

Tokio. 2012. La libertad de regulaciones con respecto a la formalidad de los edificios estimula la experimentación. Aoyama Technical College de Watanabe M. S. al fondo.

07.

Subdivisión de padrones en el área de Setagaya, Tokio.

célebres, sino que aludían en su mayoría a elementos de la naturaleza (Griffis, 1872). Esta ausencia de monumentos es en parte explicada por la falta de una autoridad central encargada del planeamiento que incentive la creación de recordatorios materiales de la historia. Según Berque (1997), en Japón el poder no se manifiesta en estructuras monumentales sino en la organización y el comportamiento social. Similarmente, Waley (2003) sostiene que Japón ha desarrollado una cultura en la que la gente concibe sus narrativas individuales y colectivas, su identidad, sin una referencia a la estructura material de la ciudad.

La postura frente a la conservación en Japón es, consecuentemente, diferente a la occidental. Respecto de la protección de edificios pertenecientes a los ciudadanos, la normativa es escasa y le otorga prioridad a la seguridad frente a la preservación. Asimismo, según Yamasaki y Waley (2003) los ciudadanos japonesas no están acostumbrados a que se limite su libertad de acción en sus propiedades, por lo que no sería fácilmente aceptado que hubiera diferencias en la afectación de terrenos en nombre de la preservación. Si bien son conservados algunos pequeños sectores del paisaje urbano tradicional (figura 12), la enorme mayoría del patrimonio histórico protegido está compuesto de edificios religiosos, antiguas villas nobles o castillos. Es 

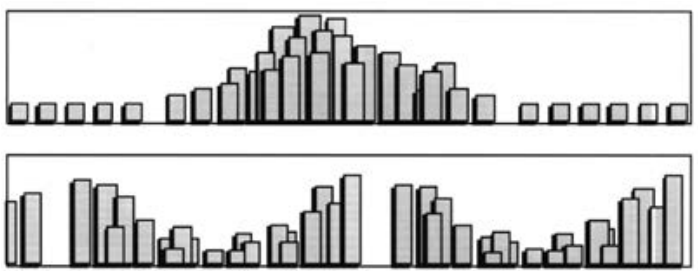

07.

08.

\section{Esquema comparado de desarrollo en altura del perfil urbano} (occidental arriba, japonés abajo).

09 .

Tokio. 2012. Variedad de resoluciones formales de fachadas.

importante notar que la conservación en Japón permite modificaciones de materiales y formas mucho mayores a las que serían admitidas en Occidente. El reemplazo parcial o total de los materiales originales, por ejemplo, es un procedimiento normal durante la reparación de edificios históricos. El caso más extremo ocurre en el santuario Ise, donde el templo es reemplazado cada veinte años por una construcción totalmente nueva pero igual, lo que para los japoneses no afecta su condición de original. De manera menos dramática, en cualquier edificio histórico los materiales pueden ser cambiados gradualmente hasta que lo único que permanece del original es la forma. Los agregados constructivos hechos para responder a nuevas tendencias o necesidades son de igual forma considerablemente tolerados. ${ }^{9}$ Esta concepción diferente de la preservación llevó a la iniciativa de la creación del Documento de autenticidad de Nara, en 1994, surgido tras la crítica de profesionales occidentales hacia los criterios japoneses de reconstrucción. El documento de Nara estableció que se deben juzgar las decisiones de conservación dentro de su contexto cultural, desafian-

9. Las controversias respecto de quienes modificaron ruinas de valor histórico, como sir Arthur Evans en Creta o Édouard Corroyer en el Mont Saint-Michel, no hubieran existido en Japón. Para más análisis sobre este tema ver Kallberg, L. J. (2015) mencionado en la bibliografía.

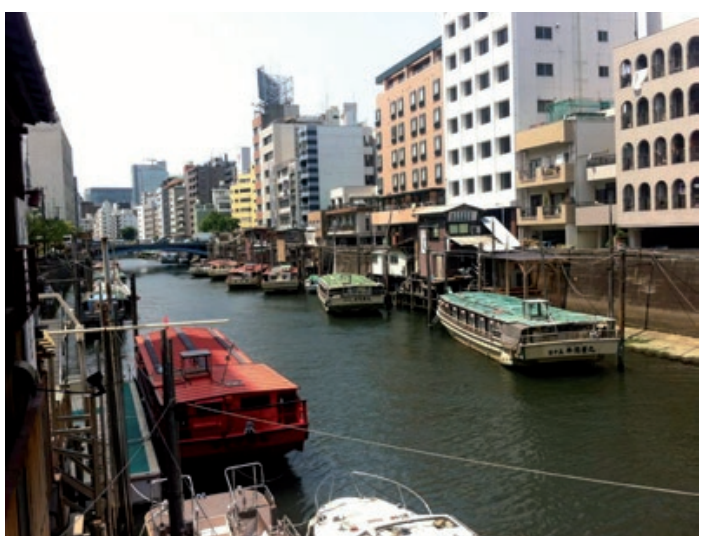

09.

do a las normas universales planteadas anteriormente por la UNESCO, basadas en criterios europeos. Se reconoció que la materialidad está ligada a condiciones intangibles como la tradición, la función y el espíritu (Cameron \& Inaba, 2015).

\section{VITALIDAD}

A pesar de las críticas hacia las ciudades japonesas, una de sus cualidades, reconocida y apreciada por los occidentales desde un comienzo, fue su vitalidad. Visitantes como Frank Lloyd Wright (1967 [1912]) y Bruno Taut (1937) apreciaron las calles comerciales incluso desde el punto de vista estético, único punto en el que la ciudad japonesa era reconocida como superior a las occidentales. Como fue explicado anteriormente, la calle es el principal espacio público de las ciudades de Japón. Esto comenzó a partir del período Tokugawa (1603-1868) gracias al ascenso de la clase comerciante urbana, que hasta mediados del siglo XVII ocupaba el estrato más bajo en el sistema social por ganar dinero sin producir ningún bien. Con el establecimiento del libre comercio, los negociantes ganaron poder y estatus. Los locales se colocaron con sus frentes abiertos hacia las calles de mayor tránsito, como las que conducían a los templos, consolidándolas así como centro de ac- 


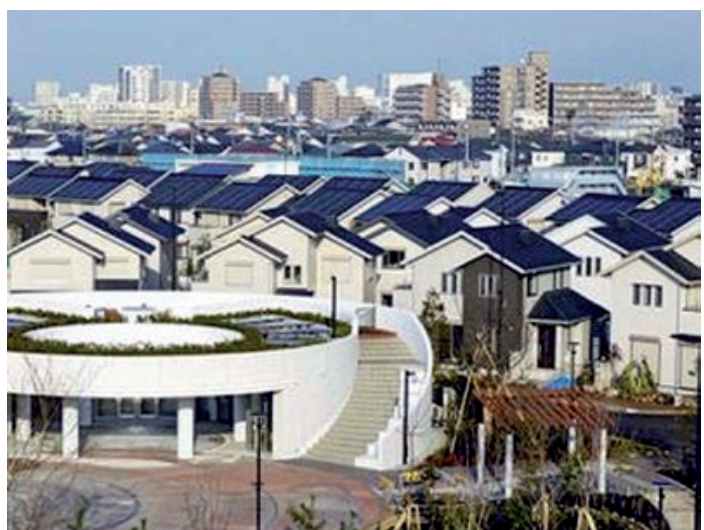

10.

tividad, y dándole un gran impulso al desarrollo de la vida urbana. A pesar de los grandes cambios ocurridos en Japón, la vitalidad se mantiene como característica distintiva. El hecho de que nunca se haya realizado una zonificación significativa -y que a pesar de los cambios se mantuvo una mezcla saludable de funciones- ayudó a mantener la actividad urbana (Shelton, 1999).

Tras examinar el estilo de vida urbano de la cultura japonesa se advierten dos tipos de actividad: las particulares y las colectivas. El tamaño reducido de las viviendas, sobre todo en las grandes ciudades, las convierte en lo que Ashihara (1992) Ilama «casas dormitorio». Gran parte de las actividades particulares que en Occidente ocurren en la vivienda o en los lugares de trabajo, en Japón se ven trasladadas a otros espacios de la ciudad. Los restaurantes sirven de comedor y salas de reunión familiar, los salones de estudio públicos y cafeterías son centros de tertulia para estudiantes de todas las edades, mientras que lecciones y reuniones de trabajo ocurren constantemente en locales de todo tipo, desde atrios de centros comerciales hasta salas de karaoke. Del mismo modo los espacios públicos abiertos se convierten en escenarios para los constantes ensayos de grupos de baile, teatro o música. La necesidad de establecimientos que puedan albergar este tipo de actividades particulares genera una altísi-
10.

\section{Desarrollo de suburbio por Panahomes en Fujisawa, cerca de Yokohama.}

\section{Plaza de juegos creada} en espacio residual. Tokio.

12

Distrito de Gion. Kioto.

Área urbana tradicional protegida.

ma concentración de locales en las áreas centrales, que ocupan no solo los espacios adyacentes a la calle sino que se expanden hacia los pisos superiores y subsuelos. De esta forma, muchos edificios de apartamentos cercanos a áreas centrales son invadidos por pequeños cafés, bares y tiendas que ocupan sus pequeñas unidades.

A las actividades particulares cotidianas que se llevan a cabo en la ciudad se les suma una infinidad de actividades de carácter colectivo, muchas de ellas de origen religioso. Parte invariable de las escenas de la vida urbana japonesa son las excursiones de paseo educativas o turísticas de escuelas y clubes, que tienen su origen en la larga tradición del peregrinaje en grupo (Rodríguez del Alisal, 2007). Los templos budistas y santuarios sintoístas tienen además un calendario muy intenso de ceremonias y celebraciones de carácter más bien festivo que atraen a un gran número de gente. Existen igualmente varias tradiciones de celebración al aire libre relacionadas con la naturaleza que están fuertemente asociados a la conciencia de la transitoriedad. Estas costumbres incluyen eventos como la contemplación de la luna llena, de las luciérnagas, de las hojas otoñales, o la famosa contemplación de las flores de cerezos, de origen ritual -el hanami-, durante la cual los parques, templos y jardines se ven col- 


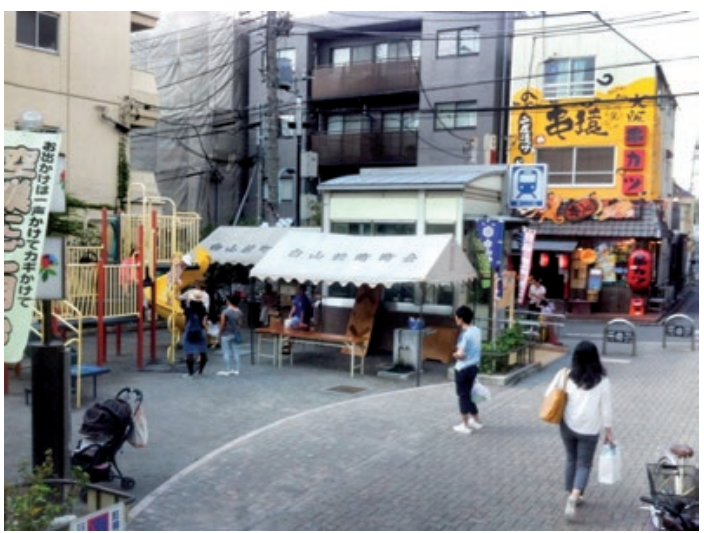

11.

mados de grupos celebrando los tradicionales picnics. La socióloga Eiko Ikegami identifica esta actividad Ilamándola «socialización estética» (Ikegami, 2005, p. 159). La tradición del hanami tomó impulso tras el florecimiento de la clase comerciante, en el siglo XVII. En estos encuentros ocurría una mezcla de clases sin precedentes en la sociedad japonesa, y si bien hoy sus participantes ignoran el original ritual o su significado en el desarrollo social, este evento, junto a las demás actividades colectivas, mantiene su rol de integrador de la sociedad urbana.

\section{CONSIDERACIONES FINALES}

Desde la apertura de Japón al mundo, la cultura occidental encontró en este país una importante fuente de comparación y reflexión, puesto que a pesar de ser sumamente diferentes, su cultura, arte y valores eran considerados «avanzados» (Befu y Kreiner, 1992). La cultura japonesa continúa desafiando los puntos de vista occidentales dominantes, y las diferentes lógicas de sus ciudades despiertan el interés de académicos internacionales. La vitalidad que las ciudades japonesas poseen tan intrínsecamente, por ejemplo, interesa especialmente a los autores occidentales (Shelton, 1999; Sorensen, 2004; Bognar, 1998) debido a que la

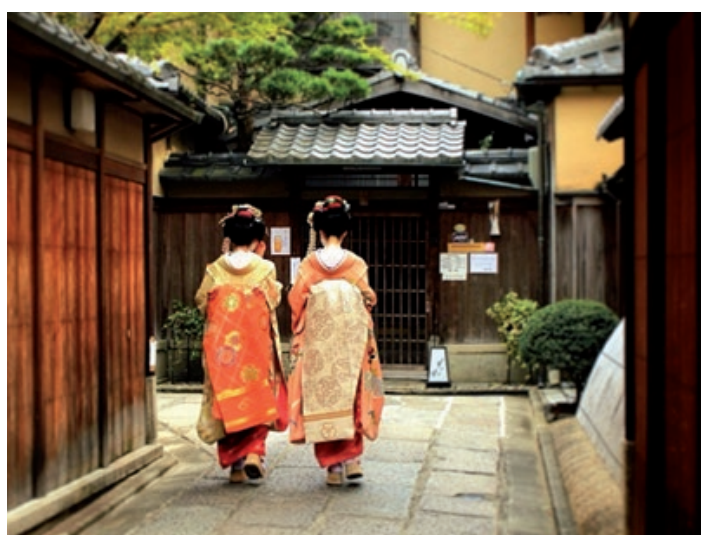

12.

recuperación de la actividad social ha sido un tema que preocupa desde hace varias décadas.

Por otro lado, para comprender la influencia creciente de la arquitectura japonesa es necesario entender el contexto urbano del que surge. El dinamismo y la libertad de acción en cuanto a normativas en las ciudades de Japón generan, por un lado, el controversial paisaje caótico, pero al mismo tiempo han posibilitado concepciones arquitectónicas como las del movimiento metabolista. El dinamismo, sumado a la aceptación por la cultura japonesa del carácter transitorio de las construcciones, promueven hoy más que nunca la experimentación, especialmente en la espacialidad de viviendas, dando lugar a las reconocidas obras de las nuevas generaciones de arquitectos, como Ryue Nishizawa o el Atelier Bow-wow.

Con relación a la creación del paisaje urbano, la flexibilidad de la ciudad japonesa se encuentra en oposición al relativo rigor de las estructuras que dan forma a la ciudad occidental. Pero si bien esta estructuración clara posibilita la creación de paisajes urbanos coherentes y unificados, no representa necesariamente un beneficio, según el criterio de algunos arquitectos japoneses como Toyo Ito (Bognar, 1997), que ven a la ciudad occidental como un museo. A su vez, el diverso 
paisaje urbano de Japón no parece preocupar demasiado a los profesionales japoneses, mientras que desde el punto de vista occidental esta imagen urbana resulta de alguna manera molesta. Según Ashihara (1992), la imprecisión del contorno urbano se encuentra en realidad en consonancia con el pensamiento japonés y su afinidad con los conceptos ambiguos, mientras que el pensamiento dualista occidental tiende a ignorar estos asuntos, lo que se ve reflejado en el orden aparente y explícito de sus ciudades. La flexibilidad de las ciudades occidentales, según notó Maraini (1995), se da principalmente en las construcciones que son lo suficientemente fuertes para admitir modificaciones y adaptaciones a diferentes usos, mientras que la construcción tradicional japonesa no tiene esta flexibilidad debido a su materialidad ligera que no permite este tipo de adaptaciones.

Con respecto a la preservación en las ciudades, a pesar de la transitoriedad de las construcciones su identidad se mantiene debido a la continuidad, la cual les da su forma. De la misma manera que el poder y la identidad de la sociedad japonesa se representan a través de tradiciones, comportamiento y estructura social (Berque, 1997; Waley, 2003), las ciudades japonesas conservan su carácter no a través de la preservación de materialidades y formas sino en la continuidad de sus procesos y estructuradores.

RECIBIDO: 8 de noviembre de 2015 ACEPTADO: 1 de diciembre de 2015 . 


\section{BIBLIOGRAFÍA}

AVELINE-DUBACH, N. (2014). «New Patterns of Property Investment in "Post-Bubble" Tokyo. The Shift from Land to Real Estate as a Financial Asset», en Globalization and New Intra-Urban Dynamics in Asian Cities. Taipei: National Taiwan University Press, pp. 265-294.

ASHIHARA, Y. (1983). The Aesthetic Townscape. Cambridge, MA: MIT Press.

- (1992). The Hidden Order. Tokyo Through the Twentieth Century. Tokio: Kodansha International.

BARTHES, R. (1983 [1970]). The Empire of Signs. Nueva York: Hill and Wang.

BEFU, H. \& KREINER J. (1992). Othernesses of Japan. Historical and Cultural Influences on Japanese Studies in Ten Countries. Múnich: Iudicium.

BERQUE, A. (1976). Le Japon. Gestion de l'espace et changement social. París: Flammarion.

- (1997). Japan. Cities and Social Bonds. Northamptonshire, UK: Pilkington Press.

- (2004). Le sens de l'espace au Japon. Vivre, penser, bâtir. París: Arguments.

BOGNAR, B. (1997). «What Goes Up Must Come Down. Recent Urban Architecture in Japan», en Harvard Design Magazine, 3, pp. 1-8.

- (1998). Tokyo. World Cities. Nueva York: Wiley \& Sons.

BOORSTIN, D. (1986). «The Japanese Conquest of Time. The Art of Renewal», en Architectural Magazine, Special Lectures, 101. Architectural Institute of Japan (1250), pp. 48-56.

BRASOR, P. \& TSUBUKU, M. (2011, diciembre 6). «If You Can't Afford the Land, Why Not Just Buy the House?», en The Japan Times. Community. Recuperado de http://www. japantimes.co.jp/community/2011/12/06/how-tos/ if-you-cant-afford-the-land-why-not-just-buy-thehouse/\#.Vom25dThBkp

CAMERON, C. \& INABA, N. (2015). «The Making of the Nara Document of Authenticity», en APT Bulletin International, 46 (4), pp. 30-37.

CRIFFIS, W. E. (1872). «The Street and Street-Names of Yedo», en Transactions of the Asiatic Society of Japan. Octubre, pp. 20-29.
HEIN, C. (2016). «Japanese Cities in Global Context», en Journal of Urban History, 42 (3), pp. 463-476.

IKEGAMI, E. (2005). Bonds of Civility. Aesthetic Networks and the Political Origins of Japanese Culture. Nueva York: Cambridge University Press.

INUI, K. \& NISHIDA, O. (2012). «Generación sin palabras. Lo pequeño, lo híbrido, lo fluido: unas señas de identidad», en Arquitectura Viva, 142.

ISOZAKI, A. (1993 [1966]). «Invisible City», en Ockman, J. y Eigen E. (eds.), Architecture Culture, 1943-1968. A Documentary Anthology, pp. 402-407.

KALLBERG, L. J. (2015). «From Restoration to Redemption», en American Society for Aesthetics Graduate, E-Journal 8.1

KINOSHITA, R. (2003). «Preservation and Revitalization of Machiya in Kyoto», en Walley, P. y Fiévé, N. (eds.), Japanese Capitals in Historical Perspective. Londres: Routledge-Curzon, pp. 347-366.

KUROISHI, I. (2016). «Urban Survey and Planning in Twentieth-Century Japan. Wajiro Kon's "Modernology" and its Descendants», en Journal of Urban History, 42 (3), pp. 557-581.

KUROKAWA, K. (1991). Intercultural Architecture. The Philosophy of Symbiosis. Londres: Academy Editions.

LOEFFLER, B. (2013). Beate Review en Brumann, C. y Schulz, E. (eds.). Urban Spaces in Japan. Cultural and Social Perspectives. H-Japan, H-Net Reviews.

MAKI, F. (1978). «Japanese Cities and the Concept of Oku», en Japan Architect, 54 (265), pp. 50-62.

MASSER, I., SHAPIRA, P. \& EDGINGTON, D. (eds.) (1994). Planning for Cities and Regions in Japan. Liverpool: Liverpool University Press.

NEIVA, S. \& RIGHI, R. (2008). «Importância da cultura na construção do espaço urbano no Japão», en Pós. Revista do Programa de Pós-Graduação FAUUSP, 15 (24).

NITSCHKE, G. (1966). «Ma. The Japanese Sense of Place», en Architectural Design, 36 (3), pp. 113-156.

OSARAGI, T. (2014). «Stochastic Models Describing Subdivision of Building Lots», en Procedia Environmental Sciences, 22, pp. 352-365. 
OSHIMA, K. T. (2016). «Rediscovering Japanese Urban Space in a World Context», en Journal of Urban History, 42 (3), pp. 623-633.

RODRÍGUEZ del ALISAL, M. (2007). «New Forms of Pilgrimage in Japanese Society», en Ackermann, P. Martínez D., Rodríguez del Alisal, M. (eds.) Pilgrimages and Spiritual Quests in Japan. Londres: Routledge. pp. 71-79.

SHELTON, B. (1999). Learning from the Japanese City. West Meets East in Urban Design. Nueva York: E\&FN SPON/ Routledge.

SORENSEN, A. (2001). «Building Suburbs in Japan. Continuous Unplanned Change in the Urban Fringe», en The Town Planning Review, 3 (72), pp. 247-273.
- (2004). The Making of Urban Japan. Cities and Planning from Edo to the Twenty-First Century. Londres-Nueva York: Routledge.

TAUT, B (1937). Houses and People of Japan. Tokio: Sanseido.

WRIGHT, F. L. (1967 [1912]). Japanese Print. An interpretation. Nueva York: Horizon Press.

YAMASAKI, M. \& Walley, P. (2003). «Kyoto and the Preservation of Urban Landscape», en Waley, P. y Fiévé, N. (eds.) Japanese Capitals in Historical Perspective. Londres: Routledge Curzon, pp. 367-384. 


\section{FUENTES DE IMÁGENES}

01. Archivo de imágenes del Nichibunken (International Research (enter for Japanese Studies). Early Photographs Database. Recuperado de: http://db.nichibun.ac.jp/en/d/ KSA/info/YAo61/

02. Hall, Robert B. The Yamato Basin, Japan, Annals of the Association of American Geographers, 22 (4), pp. 243292, 1932, p. 287

03. Autor: Tyana Santini.

04. Autor: Tyana Santini.

05. Autor: Tyana Santini.

06. Autor: Tyana Santini.
07. Osaragi, T. (2014). «Stochastic Models Describing Subdivision of Building Lots», en Procedia Environmental Sciences, 22, p. 354.

08. Shelton, B. (1999). Learning from the Japanese City. West Meets East in Urban Design. Nueva York: E\&FN SPON/ Routledge, p. 5.

09. Autor: Tyana Santini.

10. Fujisawa Trade News. Recuperado de: http://fujisawa. trade/news

11. Autor: Yaron Silberberg.

12. Autor: Alicia Pavetti. 